\title{
Modeling Instruction pada Materi Fisika Modern
}

\author{
Dian Wahid Hermawan ${ }^{\text {a) }}$, Sutikno ${ }^{\text {b) }}$, Masturi ${ }^{\text {c) }}$ \\ Program Studi Magister Pendidikan Fisika, PPs Universitas Negeri Semarang \\ Jl. Bendan Ngisor, Sampangan, Semarang, 50233

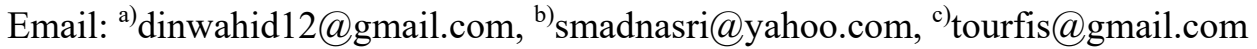

\begin{abstract}
Learning the physics is learning about scientific models that are conceptual models of physics phenomenon. The model can be as the explanation or description from analogical thinking process. The basic principal of model is its ability to predict although it has limitation. Mental model is psychological description about nature phenomenon that we are observed. In this paper, we will discuss student mental model about modern physics and the implementation of modeling instruction in the learning of modern physic. Modeling instruction uses the principles of mental construction process from scientist to construct modern physic concepts. This method tries to organize basic models become into basic pattern. According to some studies of students mental model, most of the student still think using classical model mental when they learn modern physics concepts. Applying modeling instruction methods in the learning process have purpose to modify it gradually which including revision and enrichments. With this modification, the students misconception about modern physics which caused by classical model mental will change becomes right concept.
\end{abstract}

Keywords: Modern Physics, Modeling Instruction, Mental Model, Scientific Model,

\begin{abstract}
Abstrak
Belajar konsep fisika adalah belajar tentang model-model saintifik yaitu model konseptual tentang fenomena-fenomena yang ada di alam. Model bisa berupa penjelasan atau deskripsi dari proses berfikir analogi. Prinsip dasar dari suatu model adalah memiliki kemampuan untuk memprediksi, meskipun terbatas dengan syarat-syarat batas tertentu. Sedangkan model mental adalah gambaran psikologi didalam pikiran tentang fenomena alam yang kita amati. Dalam makalah ini akan dibahas tentang model mental siswa pada konsep-konsep fisika modern, penggunaan modeling instruction untuk membelajarkan model saintifik dari konsep fisika modern. Modeling instruction adalah pembelajaran dengan menerapkan prinsip konstruksi mental para ilmuan fisika dalam merumuskan suatu teori. Metode ini mencoba mengorganisir sejumlah model-model dasar menjadi pola-pola dasar. Berdasarkan data dari beberapa penelitian didapatkan hasil bahwa kebanyakan siswa masih berfikir menggunakan model mental klasik dalam pembelajaran fisika modern. Penerapan metode modeling instruction ini bertujuan agar terjadi modifikasi secara bertahap pada model mental klasik siswa, yang meliputi revisi dan enrichment. Dengan modifikasi ini maka diharapkan miskonsepsi siswa pada konsep fisika modern yang disebabkan model mental fisika klasik dapat menjadi konsep yang benar.
\end{abstract}

Kata-kata kunci: Fisika Modern, Modeling Instruction, Model Mental, Model Saintifik, 


\section{PENDAHULUAN}

Belajar konsep fisika adalah belajar tentang model saintifik yaitu model konseptual dan model matematik dari fenomena alam. Model saintifik terbentuk dari kontruksi model mental para ilmuan fisika yang merupakan hasil dari interpretasi fenomena alam (Nersessien 1992). Model adalah bagian utama dari sains yang merepresentasikan ide, obyek, fenomena atau suatu system (Silva 2006). Sebagai contoh, Einstein mengemukakan model mental cahaya sebagai buntelan-buntelan foton untuk menjelaskan fenomena efek fotolistrik.

Dalam fisika telah terjadi banyak loncatan-loncatan pemikiran dari klasik menuju ke kuantum. Hal ini dikarenakan teori klasik telah gagal men-jelaskan tentang fenomena-fenomena fisika modern seperti radiasi benda hitam, efek fotolistrik dan hamburan Compton. Loncatan pemikiran bisa berupa terbentuknya konsep yang baru contohnya konsep spin dalam mekanika kuantum, atau konsep yang lama dalam sistem yang baru contohnya konsep massa dan medan dalam relativitas atau bisa disebut sebagai konsep turunan dari yang sudah ada (Nersessien 1992). Untuk mempelajari perubahan konsep dalam fisika modern ini maka perlu suatu metode belajar yang tepat agar tidak terjadi miskonsepsi pada siswa. Maka dalam paper ini akan dibahas tentang metode pembelajaran modeling instruction dalam fisika modern.

Model konseptual adalah gambaran dari fenomena alam yang sesuai dengan pengetahuan para ilmuan dan bisa berupa rumus matematis, pengetahuan analogi, grafik, atau model material tertentu (Ornek 2008). Sederhana atau kompleknya suatu model konseptual tergantung dari model mental siswa. Guru dapat membantu mem-visualisasikan kekomplekan dari suatu fenomena alam dengan mengenali model mental siswa dan membangkitkannya (Shepardson 2007).

Sedangkan secara bahasa, model adalah representasi tiga dimensi dari objek atau bentuk tiruan dari sebuah benda (Edward-Leis 2012). Dalam fisika, model bisa berupa bentuk tiruan yang ideal dari suatu fenomena alam. Model mental dibentuk otak untuk tujuan menyederhanakan fenomena alam menjadi model-model fakta seperti model benda dan model interaksinya (Etkitna, Warren \& Gentile 2005). Contohnya konsep gerak parabola merupakan model dari fenomena alam dengan mengabaikan gesekan udara.

Model mental adalah gambaran yang tercipta dalam pikiran tentang suatu fenomena alam atau pencitraan dari suatu obyek (Ornek 2008). Model mental spasial biasanya berkembang ketika kita mempelajari tata letak dari suatu daerah baru dan juga dapat meningkatkan ingatan spasial kita (Brunye \& Taylor 2008). Model tersebut bersifat dinamis dan berupa gambaran atau interpretasi internal yang dapat memanipulasi pikiran untuk menjelaskan, memahami dan memprediksi suatu fenomena alam (Vosniadou 1994, Greca \& Freire 2003). Model ini tercipta dari interaksi secara kontinyu antara pikiran dengan alam untuk menghasilkan pemahaman melalui proses interpretasi internal (Edward-Leis 2012).

Teori model mental yang mendasari metode pem-belajaran instruction modeling dalam fisika mencoba mengorganisir sejumlah model-model dasar menjadi pola-pola dasar (Brewe 2006). Biasanya miskonsepsi terjadi pada model-model dasar, yaitu berupa pemahaman salah pada konsep yang telah dipelajari sebelumnya (Singh, Belloni, \& Christian 2006). Metode instruction modeling ini diterapkan agar terjadi modifikasi secara bertahap pada model mental siswa yang meliputi revisi dan enrichment (Vosniadou 1994). Revisi adalah perubahan miskonsepsi menjadi konsep yang benar, sedangkan enrichment adalah penambahan informasi yang baru pada struktur mental yang sudah ada. Melalui metode ini diharapkan dapat mengembangkan kemampuan analogi, model dan modeling sebagai ciri utama ter-bentuknya teori dalam sains, maka pembelajaran fisika dengan metode modeling adalah belajar membangun hubungan antara teori dan fenomena alam (Silva 2006).

\section{HASIL DAN PEMBAHASAN}

\section{Model Mental Siswa Tentang Fisika Modern}

Pembelajaran dalam modeling instruction adalah konstruksi dari model-model mental dengan representasi pengetahuan awal siswa yang berupa pengetahuan prosedural, deklaratif dan eksperimental (Brewe 2006). Pengetahuan yang dibangun oleh fisika modern berbeda dengan fisika 
klasik. Pengetahuan pada fisika modern berdasarkan dari pengalaman yang diturunkan (derived experience) salah satunya adalah konstruksi konsep baru fisika modern berasal dari konsep fisika mekanika klasik dengan definisi-definisi yang ber-beda atau arti khusus (Bethge \& Niedderer 2010). Dalam fisika klasik ada pe-ngertian konsep sehari-hari yang dipakai untuk men-jelaskan fenomena fisika modern yang terkadang tidak tepat penjelasannya (Olsen 2002).

Dalam fisika modern, konsep model telah berubah dari representasi gambar menjadi kesamaan struktural yang menghubungkan yang berdampak pada metode pembelajaran yang berbeda (Bethge \& Niedderer 2010). Contoh dari model sebagai representasi gambar adalah model mental siswa tentang perambatan bunyi yaitu model entitas, bunyi merambat di ruang vakum dan tidak perlu medium atau bunyi adalah partikel dan mempunyai massa (Hrepic, Zollman \& Rebello 2010). Tentunya model mental seperti ini adalah model yang salah. Menariknya, bahwa model mental siswa sebagai hasil respon terhadap fenomena alam tidak ada hubungan signifikan dengan umur, jenis kelamin, dan etnik (Panagiotaki, Nobes \& Potton 2009).

TABEL 1. Model mental siswa pada beberapa materi fisika modern






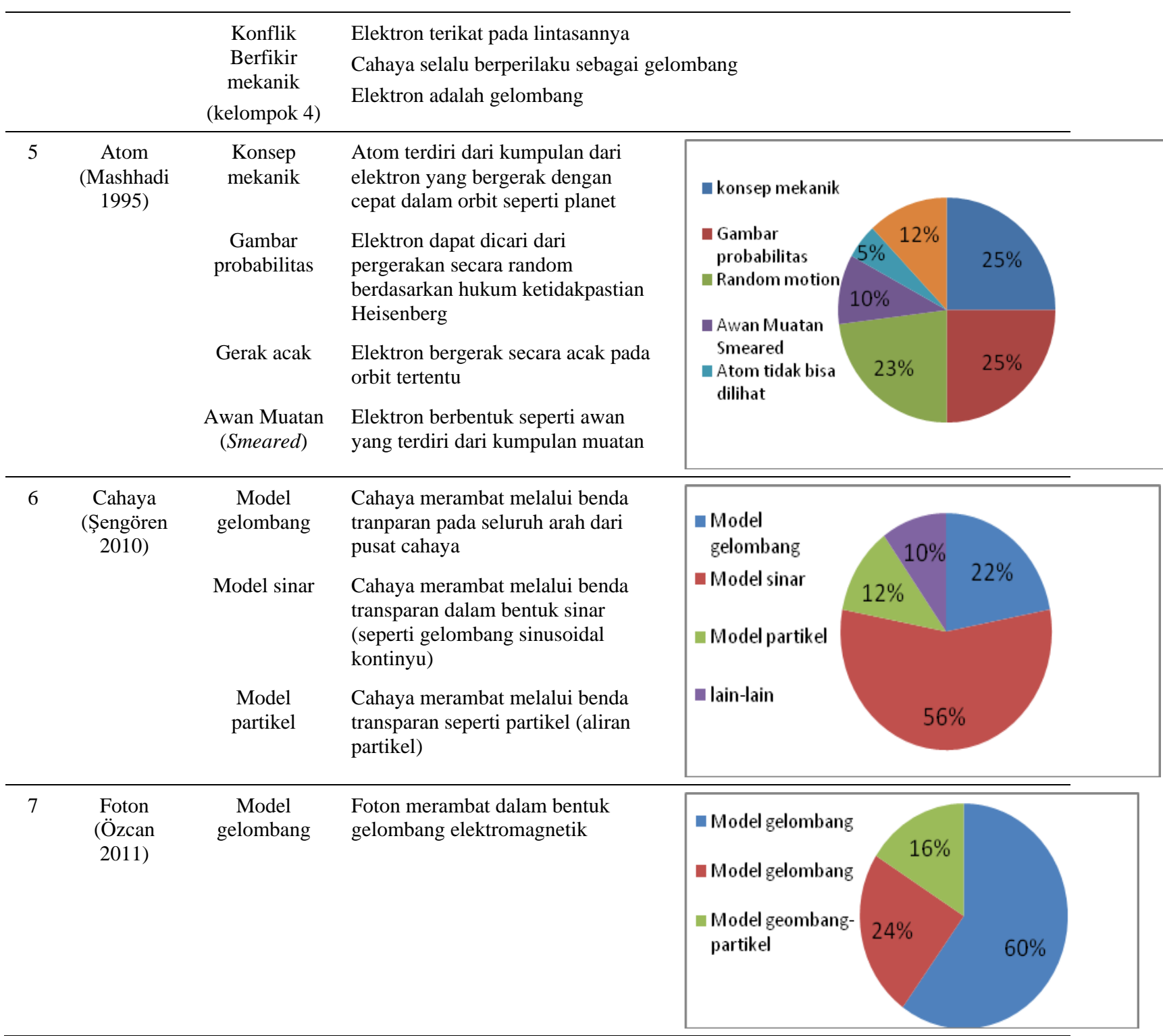

Dari beberapa penelitian model mental siswa yang berkaitan dengan materi fisika modern, seperti pada TABEL 1, didapatkan temuan-temuan bahwa sebagian besar dari siswa masih berfikir menggunakan model mental fisika klasik dalam belajar fisika modern. Contohnya, menurut Bethge \& Niedderer (2010), kebanyakan siswa men-jelaskan orbit elektron menggunakan konsep orbit lintasan yang mirip dengan orbit planet. Dalam konsep spin, siswa mendefinisikannya sebagai momentum sudut anguler dan rotasi elektron pada sumbu putarnya sehingga tidak bisa dianalogikan. Karena definisi ini menyebabkan kecepatan rotasi dari elektron akan melebihi dari kecepatan cahaya dan ini tidak sesuai dengan hasil eksperimen (Özcan 2013).

Pada tabel nomor 4 tentang topik elektron, Ireson (2000) menggunakan intrumen 40 item pertanyaan pada 190 siswa. Dari 40 item pertanyaan ini dia membagi model mental siswa menjadi 4 kelompok. Hasil dari penggolongan ini dapat diketahui bahwa terjadi konflik berfikir pada siswa kelompok 2 dan kelompok 4. Sedangkan kesimpulan yang didapat dari eksperimen ini adalah siswa tidak bisa menginterpretasikan teori kuantum tanpa menggunakan teori klasik.

Selain itu beberapa miskonsepsi yang dialami siswa dalam materi fisika kuantum adalah Jika nilai ekspektasi dari observable matter adalah nol pada keadaan awal, maka akan bernilai nol sepanjang waktu. Model mental penyebabnya adalah jika kecepatan awal benda nol maka percepatan benda akan nol. Konsep kedua yang miskonsepsi adalah jika fungsi $\mathrm{x}$ ortogonal dengan fungsi y maka hasil perkalian dari operator spin $\mathbf{S}_{\mathbf{x}}$ dan $\mathbf{S}_{\mathbf{y}}$ dari keadaan eigen adalah juga ortogonal dan penyebabnya adalah pandangan klasik yaitu vektor $\mathbf{i}$ dan $\mathbf{j}$ yang ortogonal maka $\mathbf{i} . \mathbf{j}=0$ (Singh, Belloni, \& Christian 2006). Jadi penyebab miskonsepsi ini adalah penggunaan model mental fisika klasik untuk 
menganalogikan konsep dari fisika kuantum. Oleh sebab itu salah satu saran untuk pembelajaran fisika kuantum adalah menghindari model mental dari fisika klasik dalam belajar fisika kuantum (Olsen 2002).

Dari tabel data model mental siswa didapatkan bahwa kebanyakan siswa memiliki model mental yang bersifat tidak komplit, tidak stabil dan tidak ilmiah (Greca \& Moreira 2000). Ketidakkomplitan ini disebabkan karena siswa masih berfikir dalam fisika klasik. Oleh sebab itu kita perlu menerapkan metode belajar modeling instruction sehingga dapat membantu siswa dalam meng-konstruksi model mentalnya agar sesuai dengan model saintifik yang bersifat konsisten. Siswa yang memiliki model mental klasik dan berfikir tanpa model dapat mengalami proses revisi menjadi model mental kuantum. Sedangkan siswa yang memiliki model mental kuantum dapat mengalami proses enrichment. Selain itu siswa juga harus dapat menghubungkan antara satu konsep dengan konsep yang lain (Gaffney 2004).

\section{Modeling Instruction}

Metode pembelajaran yang dikembangkan oleh Universitas Colorado pada materi fisika modern adalah metode riset yang meliputi pertanyaan konsep, peer instruction, simulasi komputer. Metode ini dapat mengembangkan kemampuan siswa dalam membangun model reasoning, dan hubungan antara masalah dalam fenomena alam (Baily \& Finkelstein 2007). Sedangkan tutorial kuantum yang dikembangkan oleh Singh, Belloni dan Christian (2006) menekankan pada penggunaan alat bantu visual untuk membangun intuisi fisika (model mental) tentang fenomena kuantum dan mengembangkan kemampuan memprediksi pada situasi tertentu. Jadi modeling instruction adalah metode yang menggunakan prinsip umum dari model yang berupa penyederhanaan dari fenomena kuantum, penjelasan dari fenomena kuantum dan memiliki kemampuan memprediksi meskipun terbatas (Etkitna, Warren \& Gentile 2005).

Brewe (2006) menyusun sintaks dari modeling instruction seperti pada TABEL 2 yang terdiri dari langkah-langkah pembelajaran sebagai berikut, pembukaan dan representasi fisis, koordinasi dari representasi, pengenalan aplikasi, aplikasi, abstraksi dan kesimpulan dan pengembangan.

TABEL 2. Sintaks pembelajaran modeling instruction

\begin{tabular}{ll}
\hline \multicolumn{1}{c}{ Kontruksi model } & \multicolumn{1}{c}{ Tujuan pembelajaran } \\
\hline Pembukaan dan representasi & $\begin{array}{l}\text { Mengenali hal-hal yang dibutuhkan dalam menyusun model yang baru seperti } \\
\text { definisi dari istilah-istilah yang baru } \\
\text { Koordinasi dari beberapa representasi }\end{array}$ \\
$\begin{array}{l}\text { Membuat grafik dan menhubungkan dengan representasi umum melalui kegiatan } \\
\text { eksperimen dan aktivitas konsep yang lainnya }\end{array}$ \\
Pengenalan aplikasi & $\begin{array}{l}\text { Membuat model konseptual dan matematis dari grafik } \\
\text { Aplikasi }\end{array}$ \\
Abstraksi dan kesimpulan & Mengidentifikasi karakteristik model representasi pada kondisi yang berbeda \\
Pengembangan lebih lanjut & $\begin{array}{l}\text { Menerapkan model konseptual yang disusun pada kondisi yang berbeda (untuk } \\
\text { mengatahui kemampuan memprediksi dari suatu model) }\end{array}$ \\
\hline
\end{tabular}

Menurut Kocakulah \& Kural (2010) penggunaan metode generative learning model teaching dengan beberapa prinsip dasar yaitu: siswa mempelajari model saintifik, guru menyediakan sintesis dari model saintifik, dan siswa mencoba mencocokkan model mentalnya dengan model saintifik yang disajikan guru, terbukti dapat mengurangi miskonsepsi siswa dan meningkatkan konstruksi model saintifik siswa. Ada beberapa metode yang berkaitan tentang model mental yaitu generative learning model teaching, analogical teaching strategy, siklus pemodelan dan pendekatan sosio-konstruktif (Baily \& Finkelstein, Well \& Hestenes 1995). Metode siklus modeling memiliki beberapa tujuan (Well \& Hestenes 1995):

a. Mengajak siswa mengkonstruksi model saintifik untuk mendeskripsikan, memprediksi dan mengontrol fenomena fisika,

b. Menyediakan alat konseptual dasar untuk memodelkan objek fisika, khususnya matematik, grafik dan diagram representasi

c. Membiasakan siswa dengan model dasar sebagai inti konsep dari fisika 
d. Mengembangkan pengetahuan dari struktur pengetahuan saintifik dengan menyelidiki kesesuaian model mental siswa dengan teori.

e. Membuktikan bagaimana memvalidasi pengetahuan saintifik dengan cara mengevaluasi model saintifik dengan data empiris

f. Mengembangkan kemampuan modeling sebagai prosedur inti untuk mempelajari pengetahuan saintifik

Desain pembelajaran berbasis modeling instruction menurut Well, Hestenes (1995) dan Jackson,

Dukerich, Hestenes (2008) adalah student-centered instructional yaitu;

a. Pembelajaran siklus modeling melibatkan siswa pada semua tahapan pengembangan model meliputi evalusi dan penerapannya

b. Guru mengatur kegiatan belajar siswa, biasanya dengan demontrasi dan diskusi kelas untuk membangun pemahaman umum tentang permasalahan yang dicari.

c. Siswa membuat kesimpulan secara lisan ataupun tertulis yang meliputi rumusan dari modelmodel dari fenomena alam dan mengevaluasinya dengan mem-bandingkan dengan data.

d. Guru membimbing siswa dengan menjelaskan istilah dan konsep yang terkait, untuk memperjelas model mental siswa dan meningkatkan diskusi siswa.

e. Guru mencatat perkembangan siswa dan membimbing secara inkuri dengan tipe pertanyaan sokratis.

f. Guru didukung dengan data model mental awal dari siswa, baik yang miskonsepsi maupun yang benar. Data ini digunakan agar siswa mampu mengungkapkan, menganalisis dan membenarkan model mental yang salah tersebut.

Mengajarkan bagaimana siswa bisa meng-kontruksi model mental dalam fisika kuantum berbeda dengan fisika klasik. Dua hal yang membedakan teori kuantum dengan teori klasik adalah kuantisasi dan ketidakpastian dalam hasil pengukuran (Mashhadi \& Woolnough 1997). Kuantisasi adalah berfikir diskrit tentang sesuatu yang kontinyu. Cahaya yang dianggap gelombang oleh fisika klasik dipostulatkan oleh Einstein terdiri dari kumpulan partikel foton yang diskrit. Kuantisasi dari suatu medan berarti bergetarnya suatu medan yang dibatasi oleh energi-energi yang diskret dan ketika berinteraksi dengan layar energi dari medan hilang dan terdeposit pada titik terjadinya interaksi (Hobson 2005).

Proses berfikir yang dialami siswa ketika modeling ini menurut Sins, Savelsbergh \& Joolingen (2005) adalah menganalisis, berfikir induktif, mengukur (quantify), menjelaskan, mengevaluasi. Menganalisis diartikan sebagai interpretasi data empiris yang dibuat dalam bentuk tabel dan grafik. Berfikir induktif terjadi melalui perumusan hipotesa tentang bagaimana model berinteraksi dan berperilaku dan juga proses menghubungkan antara struktur model dan perilaku dari fenomena alam yang akan di-modelkan. Quantify adalah membuat model matematis dari model mental dan hubungan antara elemen-elemen model. Menjelaskan adalah mengklarifikasi hubungan antara elemen-elemem model dan faktor-faktor yang menyebabkan terjadi perubahan. Dalam mengevaluasi, siswa membuktikan kekonsistenan model dengan gambaran perilaku fenomena yang dimodelkan.

Pembelajaran pada fisika kuantum seharusnya dimulai dari konsep dasar radiasi dan materi bukan dimulai dari fenomena komplek seperti spektrum atom hidrogen (Hobson 2005) Hal ini dikarenakan siswa sudah memiliki konsep fisika klasik ketika akan belajar di kelas sehingga pengetahuan dasar yang dibawa siswa ini dapat mempengaruhi pemahaman siswa di kelas (Wittmann, Steinberg \& Redish 2002). Sedangkan Fischler and Lichtfelds dalam Olsen (2002) merekomendasikan pendekatan dalam pembelajaran fisika kuantum adalah sebagai berikut: menghindari model mental dari fisika klasik, mengajar konsep efek fotoelektrik dimulai dengan elektron bukan dengan foton, menggunakan interpretasi statistika dari fenomena yang yang diobservasi dan menghindari penjelasan dualisme, prinsip ketidakpastian Heisenberg dikenalkan pada tahap awal pembelajaran, model atom hidrogen Bohr dihindari.

\section{KESIMPULAN}

Pembelajaran dengan metode modeling instruction adalah membelajarkan konsep fisika dengan mengikuti pola pikir dari para ilmuan fisika. Karena cara kerjanya yang bersifat analogi dan pemodelan maka hal ini menjadi ciri utama dari ilmu fisika. sehingga cara kerja ini menjadi peran 
utama dari pembelajaran materi fisika, khususnya teori fisika modern yang sulit dibelajarkan dengan metode eksperimen.

Untuk menerapkan modeling instruction maka kita perlu mengidentifikasi model-model mental awal siswa. Berdasarkan data dari beberapa penelitian didapatkan hasil bahwa siswa masih berfikir menggunakan model mental fisika klasik dalam pembelajaran fisika modern. Model mental dari fisika klasik ini yang menyebabkan terjadinya miskonsepsi pada pembelajaran konsep fisika kuantum.

Beberapa metode modeling instruction yang bisa diterapkan untuk membantu siswa mengkontruksi model mental fisika kuantum adalah generative learning model teaching, analogical teaching strategy dan pendekatan sosio-konstruktivis, siklus modeling. Penggunaan metode generative learning model teaching untuk meneliti model gelombang dari cahaya terbukti dapat mengurangi miskonsepsi siswa dan meningkatkan konstruksi model saintifik siswa.

\section{UCAPAN TERIMAKASIH}

Terimakasih kepada Mahasiswa Pascasarjana UNNES prodi pendidikan fisika 2014 yang membantu dalam diskusi.

\section{REFERENSI}

Baily, C. \& Finkelstein, N. D. 2007, Teaching and understanding of quantum interpretations in modern physics courses, Phys. Rev. ST Phys. Educ. Res., vol. 6, no.1,

Bethge, T. \& Niedderer, H. 2010, 'Students' conceptions in quantum physics', Bremen.

Brewe E. 2006, "Modeling theory applied; modeling instruction in university physics", Kaneohe .

Brunye', T. T. \& Taylor, H. A. 2008, 'Working memory in developing and applying mental models from spatial descriptions', Journal of Memory and Language, vol. 58, no. 3, pp. 701-729.

Edward-Leis, C. 2012, "Challenging learning journeys in the classroom: Using mental model theory to inform how pupils think when they are generating solutions", (Stockholm,) pp. 153-162.

Etkitna, E., Warren, A. \& Gentile, M. 2005, 'The role model in physics instruction', New Brunswick, NJ, vol. 44, no. 1 , pp. 34-39.

Gaffney, J. 2004, 'Teaching for Understanding in Modern Physics: What does it look like and how might we get there?', Pittsburgh , p 1-45.

Greca, I. M. \& Freire JR, O. 2003, 'Does an Emphasis on the Concept of Quantum States Enhance Students' Understanding of Quantum Mechanics?', Journal of Science \& Education, vol. 12, p 541-557.

Greca, I. M. \& Moreira, M. A. 2000, 'Mental models, conceptual models, and modeling', International Journal of Science Education, vol. 22, pp. 1-11.

Hobson, A. 2005, Electrons as field quanta: A better way to teach quantum physics in introductory general physics courses, Arkansas, p 1-14

Hrepic, Z., Zollman, D. \& Rebello, S. 2010, 'Identifying students' models of sound propagation', Physic Journal Rev. ST Phys. Educ. Res, vol. 6.

Ireson, G. 2000, The quantum understanding of pre-university physics students, Leicestershire, pp. $15-21$.

Jackson, J., Dukerich, L. \& Hestenes, D. 2008, 'Modeling Instruction: An Effective Model for Science Education', Journal of Science Educator, vol. 17, pp. 10-17.

Kocakulah, M. S. \& Kural, M. 2010, 'Investigation of conceptual change about double-slit interference in secondary school physics', International Journal of Environmental \& Science Education, vol. 5, pp. 435-460. 
Mashhadi, A. \& Woolnough, B. 1997, 'Dualistic Thinking Underlying Students' Understanding of Quantum Physics', Maryland.

Mashhadi, A. 1995, Advanced level Physics students' conceptions of Quantum Physics, Oxford, American Journal of Physics, Vol. 48, pp 1-15.

Nersessien, N. J. 1992, 'How do scientists think? Capturing the dynamics of conceptual change in science', Cognitive Model of Science, vol. 15, pp. 3-44.

Olsen, R. V. 2002, 'Introducing quantum mechanics in the upper secondary school: a study in Norway', International Juornal of Science Education. Vol. 24 no. 6, pp. 565-574.

Ornek, F. 2008, 'Model in Science Education: Applications of models in learning and teaching science', International Juornal of envinronmental \& Science Education, Vol. 3, no. 2, pp. 35-45.

Özcan, Ö. 2011, 'What are the students' mental models about the "spin" and "photon" concepts in modern physics?', Journal Procedia Social and Behavioral Sciences, vol. 15, pp. 1372-1375.

Özcan, Ö. 2013, 'Investigation of Mental Models of Turkish Pre-Service Physics Students for the Concept of Spin', Eurasian Journal of Educational Research, vol. 52, pp. 21-36

Panagiotaki, G., Nobes, G. \& Potton, A. 2009, 'Mental models and other misconceptions in children's understanding of the earth', Journal of Experimental Child Psychology vol. 104, pp. $52-67$.

Şengören, S. K. 2010, 'Turkish Students' Mental Models of Light to explain the single slit diffraction and Double slit interference of Light: A Cross-Sectional Study', Journal of Baltic Science Education, vol. 9 no. 1, pp. 61-71.

Shepardson, D. P., Wee, B., Priddy, M. and Harbor, J. 2007, 'Students' Mental Models of the Environment', Journal Of Research In Science Teaching, vol. 44, no. 2, pp. 327-348.

Silva, C. C. 2007, 'The Role of Models and Analogies in the Electromagnetic Theory: A Historical Case Study', Journal of Science \& Education Vol. 16, No. 7, pp. 835-848

Singh, C., Belloni, M. \& Christian, W. 2006, 'Improving students' understanding of quantum mechanics, Journal of American Institute Of Physics', vol 59, no. 8, pp. 43-49,

Sins, P. H. M., Savelsbergh, E. R. \& Joolingen, W.R.v. 2005, 'The Difficult Process of Scientific Modelling: An analysis of novices' reasoning during computer-based modeling', International Journal of Science Education, vol. 27, p. 1695-1721.

Vosniadou, S. 1994, Capturing and modeling the process of conceptual change, Jurnal of learning and Instruction, vol. 4, pp 45-49.

Well, M. \& Hestenes, D. 1995, ‘A modeling method for high school physic instruction', American Journal of Physic, vol. 63, pp. 606-619.

Wittmann, M. C., Steinberg, R. N. \& Redish, E. F. 2002, 'Investigating student understanding of quantum physics: Spontaneous models of conductivity', American Journal of Physics, vol. 70, $p$ 218-226. 